\title{
Neurocognition in Patients with Acne Vulgaris
}

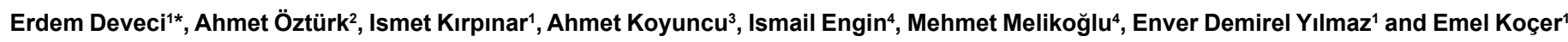

${ }^{1}$ Bezmialem Vakif University, School of Medicine, Department of Psychiatry, Istanbul, Turkey

${ }^{2}$ Dumlupınar University, School of Medicine, Department of Psychiatry, Kütahya, Turkey

${ }^{3}$ Incirli Ethica Hospital, Department of Psychiatry, Istanbul, Turkey

${ }^{4}$ Regional Training and Research Hospital, Department of Dermatology, Erzurum, Turkey

\begin{abstract}
Objective: Acne vulgaris is often associated with psychological distress, depression, and anxiety disorders that may impair neurocognitive functions such as memory, attention, psychomotor speed, and executive functions, which are also common psychiatric disorders in patients with acne.

Methods: We determined cognitive functioning in treatment naive acne patients, without a history of any psychiatric disorder. Cognitive abilities, anxiety, social phobia and depression were assessed in acne vulgaris patients and compared with healthy controls. 66 treatment naive acne patients and 47 controls were recruited. The groups were matched for age, gender, and years spent in education.

Results: The acne group demonstrated significant worse performance in cognitive tests assessing attention span, verbal episodic memory, learning, working memory, and phonemic verbal fluency when compared with controls. No group difference was found in cognitive tests assessing attention or executive functions. The acne group also had significantly higher anxiety scores (HADS-A, LSAS). We conducted Analysis of covariance (ANCOVA) to compare groups on cognitive functioning, controlling for HADS and LSAS scores. The differences between the performances of the groups in cognitive assessment remained significant after covariance.
\end{abstract}

Conclusion: As acne vulgaris is largely a disease of adolescence, a period in which academic performance has great importance, psychiatric consultation including cognitive evaluation seems to be a critical part of its treatment.

Keywords: Memory; Executive functions; Attention; Anxiety; Depression; Acne vulgaris

\section{Introduction}

Acne is the most common visible skin disease. The relationship between acne and mental health has been extensively studied [1]. Emotional stress can exacerbate acne, and acne patients may experience psychological and psychiatric problems [2]. Psychological problems associated with acne include a decrease in self-esteem, impaired overall perception of personal well-being and self-image, embarrassment, fear of rejection, social withdrawal, anger, restrictions in lifestyle, problematic family relations, and excessive mental engagement in the acne lesions [2-5]. Depression, anxiety, social phobia, and body dysmorphic disorder are common psychiatric disorders in patients with acne, and the reported prevalence of suicidal ideation and suicide completion in acne patients is remarkable [6]. The mental health impairment scores among acne patients are higher when compared with a variety of other chronic, non-psychiatric medical conditions, including epilepsy and diabetes [7]. Mallon et al. [8] compared the quality of life of 111 acne patients with that of patients with other organic diseases using the SF-36 quality of life scale and found that emotional and psychological problems in acne patients are as serious as those observed in asthma, epilepsy, diabetes, and arthritis patients.

Patients with depression, social anxiety disorder, and social phobia show neuropsychological symptoms and these disorders are common associated with impairment of neurocognitive skills, including reduced memory, attention, psychomotor speed, and executive functions $[9,10]$.

Taking into account that acne vulgaris is largely a disease of adolescence, a period in which academic performance has great importance and acne is often associated with psychiatric problems affecting cognitive functionality, it seems to be important to evaluate the impact of acne on cognitive functions.
We searched the literature and did not find any study evaluating the cognitive functions of acne patients. In our recent study on the effects of isotretinoin treatment on cognitive abilities, we found improvements in attention and executive functions during isotretinoin treatment [11]. In that study we did not aim to evaluate the baseline cognitive performances of acne patients in comparison with healthy controls and it was unclear whether the results showed an ongoing cognitive impairment before the isotretinoin treatment or not. We designed this study to answer this question and we determined the cognitive functioning in treatment naive acne patients, without a history of any psychiatric disorder, or active psychopathology.

\section{Methods}

\section{Subjects}

We recruited 66 consecutive patients referred to the dermatology outpatient clinic and 47 healthy controls matched with the patient group for age, gender and years of education. Controls were the neighbours of the hospital staff. The study protocol fulfilled the principles outlined in the Declaration of Helsinki and was approved by the local Ethics Committee. All participants were informed about the protocol and a written consent was obtained from each one.

*Corresponding author: Erdem Deveci, Bezmialem Vakıf Üniversitesi, Hastanesi Psikiyatri Kliniği Vatan Caddesi, 34093 Fatih, İstanbul, Turkey, Tel: 905055836796; Fax: 902126217580; E-mail: erdemdeveci@gmail.com

Received March 03, 2014; Accepted April 24, 2014; Published April 30, 2014

Citation: Deveci E, Öztürk A, Kırpınar I, Koyuncu A, Engin I, et al. (2014) Neurocognition in Patients with Acne Vulgaris. J Psychiatry 17: 121 doi: 10.4172/2378-5756.10001214

Copyright: ( 2014 Deveci E, et al. This is an open-access article distributed under the terms of the Creative Commons Attribution License, which permits unrestricted use, distribution, and reproduction in any medium, provided the original author and source are credited 
A thorough clinical evaluation including a detailed medical and psychiatric history, and a complete physical examination was performed for each participant (patients and controls). In addition, the diagnosis and clinical classifications of acne were determined by a dermatologist.

The Turkish equivalent of the Structured Clinical Interview for DSM-IV Axis I Disorders (SCID-I) was applied by a psychiatrist to all participants. The participants that had a diagnosis or a history of mental retardation $(\mathrm{IQ}<70)$, serious head trauma, seizures or any other mental disorder (including schizophrenia and other psychotic disorders, attention deficit hyperactivity disorder, learning disorders, pervasive developmental disorders, mood disorders, obsessive compulsive disorder, and anxiety disorders meeting the diagnostic criteria), and participants on any medical treatment were excluded. Participants with a family history (first degree relatives) of schizophrenia, bipolar disorder or schizoaffective disorder were also excluded to avoid the negative effect of these disorders on cognitive functions. The same exclusion criteria were also applied to the control group.

\section{Neurocognitive evaluation and IQ assessment}

IQ test and cognitive assessments were conducted in the test laboratory of our clinic. Optimal requirements for testing, such as room lighting, silence, and the physiological necessities of the subjects were fulfilled. To avoid the confounding effect of time of the day on cognitive functions, all the tests were applied between 09.00 and 11.00 A.M. We used Kent-EGY and Porteus labyrynths tests for the assessment of IQ. We used a neurocognitive battery, which comprised of the Rey Auditory Verbal Learning Test (RAVLT), Auditory Consonant Trigram Test (ACTT), Controlled Oral Word Association Test (COWAT), Digit Span Test (DST), Trail Making Test and Stroop Test (TMT-A/-B). The administration procedures for the neurocognitive tests used in the present study are provided below.

\section{Rey auditory verbal learning and memory test}

Verbal episodic memory and learning was assessed with the RAVLT, in which subjects were required to learn a series of words presented orally over five trials and were then asked to immediately recall them after each presentation (total recall of five trials), or after a $20 \mathrm{~min}$ delay (delayed recall). They were also asked to recognize and mark target words between distracters (recognition) on a paper. The following measures were analyzed; Total learning scores (1-5): The total number of correctly recalled words aggregated over the five learning trials. Delayed recall: The total number of correctly recalled words after the $20 \mathrm{~min}$ delay. True positives: The number of true answers that the subject was expected to mark in the recognition section of the test. True negatives: The number of true answers that the subject was expected not to mark in the recognition section of the test. Recognition percent correct score: This measure is calculated by the formula: True positives + True negatives / 50, as proposed by Harris et al. [12].

\section{Auditory consonant trigram test}

This test is used to measure attention and working memory. The subject listened to a string of three consonants (the consonant trigram), and this is immediately followed by a mental task, such as counting backward. After that task, the client was asked to recall the trigram. The total number of recalled letters was used in evaluation [13].

\section{Controlled oral word association test}

This test is a measure of phonemic verbal fluency. Subjects had to produce a maximum number of words with the given letters $(\mathrm{K}, \mathrm{A}$ and
S, according to Turkish standardization), with $1 \mathrm{~min}$ allowed for each letter [14].

\section{Digit span test}

This test measures attention and working memory. It had two sections, Digit Span Forward and Backward. In the forward section, the subject repeated the numbers told to him/her by the examiner. In the backward section, the subject repeated the numbers told to him/her backward. The participant's score was the sum of the correctly recalled numbers in the forward and backward sections, and the total correctly recalled numbers of both the sections combined [13].

\section{Trail making test}

This TMT assesses mental flexibility, visual tracking and motor abilities. It consisted of two parts $[13,15]$. In part A, dots numbered between 1 and 25 were combined with a continuous line and in part $B$, each letter was combined with a number. Part A evaluated psychomotor speed and focused attention, whereas part B measured mental flexibility [16]. In this test, the time required to complete the two separate parts was measured.

\section{Stroop test}

This test measures word-reading and colour-naming speed, and the participant's ability to inhibit reading in favour of ink-colour naming, when words were printed in colours different from those spelled out The Stroop test assessed the ability to flexibly direct attention to the presence of a distraction, inhibit a habitual behavioural pattern, and display non-usual behaviour by taking into account the individual's speed of processing in measuring resistance to interference $[13,17]$.

\section{Structured clinical interview for DSM-IV axis I disorders (SCID-I)}

SCID-I is a diagnostic exam used to determine DSM-IV Axis I disorders and covers diagnoses most commonly seen by clinicians and includes the diagnostic criteria for these disorders with corresponding interview questions. The SCID-I is divided into six self-contained modules that can be administered in sequence: mood episodes; psychotic symptoms; psychotic disorders; mood disorders; substance use disorders; and anxiety, adjustment, and other disorders. The reliability analyses of the Turkish version of SCID-I were performed as per Özkürkçügil et al. [18].

\section{Hospital anxiety and depression scale (HADS)}

The Hospital Anxiety and Depression Scale (HADS), a selfassessment scale, was developed to detect states of depression, anxiety and emotional distress amongst patients who were being treated for a variety of clinical problems. The final scale has a total of 14 items, with responses being scored on a scale of $0-3$, with 3 indicating higher symptom frequencies. Score for each subscale (anxiety and depression) can range from 0-21 with scores categorized as follows: normal (0-7), mild (8-10), moderate (11-14), severe (15-21). Scores for the entire scale (emotional distress) range from $0-42$, with higher scores indicating more distress. Prior to completing the scale patients are asked to "fill it complete in order to reflect how they have been feeling during the past week" The reliability and validity study of the Turkish version was performed as per Aydemir et al. [19].

\section{Liebowitz social anxiety scale (LSAS)}

LSAS was developed in the 1980's to facilitate the measurement of distress and impairment caused by social anxiety. The scale is comprised 
Citation: Deveci E, Öztürk A, Kırpınar I, Koyuncu A, Engin I, et al. (2014) Neurocognition in Patients with Acne Vulgaris. J Psychiatry 17: 121 doi: 10.4172/2378-5756.10001214

Page 3 of 7

of 13 items that measure fear of performance situations and 11 items that measure fear of social interaction. For each of these 24 items avoidance is also measured. The validity and reliability analyses of the Turkish version of the LSAS were performed as per Soykan et al. [20].

\section{Statistical analyses}

Statistical analysis was performed using SPSS (version 16.0). The normality distribution of test scores was tested by the KolmogorovSmirnov and Shapiro-Wilk tests. The differences between patients and controls were analyzed by Student's t-test. The values were presented as mean \pm standard deviation (SD), or percentages. Analysis of covariance (ANCOVA) was conducted to compare groups on cognitive functioning, covarying HADS and LSAS scores. All statistics are reported in two-tailed form. A $\mathrm{P}<0.05$ was considered statistically significant. A Bonferroni correction was applied to adjust for multiple comparisons.

\section{Results}

\section{Subjects}

We recruited 66 consecutive acne patients referred to the dermatology outpatient clinic and 47 healthy controls, who were matched with the patient group for age, gender and years of education,

\begin{tabular}{|l|c|c|}
\hline Grade 1 & Less than 10 inflammatory facial lesions & $\mathrm{n}=2(3.8 \%)$ \\
\hline Grade 2 & Inflammatory facial lesions: 10-20 & $\mathrm{n}=28(53.9 \%)$ \\
\hline Grade 3 & Inflammatory truncal lesions & $\mathrm{n}=20(38.5 \%)$ \\
\hline Grade 4 & Nodules and eschars on face and /or body & $\mathrm{n}=2(3.8 \%)$ \\
\hline
\end{tabular}

*Gollnick H, Orfanos C. Clinical assessment of acne. Cunliffe W, ed. Acne. Stuttgart: Hippokrates; 1993. p. 118.

Table 1: Clinical classification of acneic lesions and number of patients of each grade proposed by Orfonos* were recruited from the general population. In psychiatric evaluation of the acne patients, 3 were diagnosed with major depressive disorder, 2 with obsessive compulsive disorder, 1 with schizophrenia, two of the patients reported that one of their parents were diagnosed with schizoaffective disorder or schizophrenia and these patients were excluded from the study. 5 patients refused to complete the tests. One of them could not complete the neurocognitive assessment due to physical complaints, such as headache and dizziness. Thus, our analysis was carried out on 52 acne patients and 47 controls.

\section{Acne grades}

In the dermatological evaluation of 52 patients, acneic lesions were evaluated in 4 grades based on the localization and number of lesions, according to the classification proposed by Orfonos [21]. The number of patients representing each grade is provided in Table 1 .

\section{Socio-demographical features and IQ}

As shown in Table 2, the groups were well-matched for age, gender, socioeconomic background, years of education, the type of school, and IQ which are important factors affecting the neurocognitive assessment.

\section{Neurocognitive assessment}

The neurocognitive tests were applied by a psychiatrist. As shown in Table 3, the acne group showed significantly worse performance in verbal episodic memory, learning, working memory, and phonemic verbal fluency, as assessed with the RAVLT, ACTT, COWAT, and DST, when compared to the control group. There were no significant differences between the acne and control groups in terms of executive functioning, attention, mental flexibility, or motor abilities, as assessed by the TMT/A-B and Stroop test.

\begin{tabular}{|c|c|c|c|c|c|c|}
\hline & Acne group $(n=52)$ & Control group $(n=47)$ & Comparison (p) & $d f$ & $t$ & $x^{2}$ \\
\hline Age & $21.09 \pm 2.88$ & $21.13 \pm 3.01$ & 0.958 & 97 & -0.53 & \\
\hline Gender (\%) & & & 0.813 & 1 & & 0.56 \\
\hline Female & $43(82.7 \%)$ & $38(80.9 \%)$ & & & & \\
\hline Male & $9(17.3 \%)$ & $9(19.1 \%)$ & & & & \\
\hline Education (years) & $12.15 \pm 1.92$ & $12.09 \pm 1.95$ & 0.8606 & 97 & 0.176 & \\
\hline IQ & $104.63 \pm 8.57$ & $103.08 \pm 4.42$ & 0.255 & 77.92 & 1.15 & \\
\hline Education - Type of Schools & & & 0.998 & 3 & & 0.40 \\
\hline Primary school graduate & $4(7.7 \%)$ & $4(8.5 \%)$ & & & & \\
\hline $\begin{array}{l}\text { Student at general secondary } \\
\text { education }\end{array}$ & $11(21.2 \%)$ & $10(21.3 \%)$ & & & & \\
\hline General secondary & $14(26.9 \%)$ & $12(25.5 \%)$ & & & & \\
\hline \multicolumn{7}{|l|}{ Education } \\
\hline \multicolumn{7}{|l|}{ Graduate } \\
\hline Student at university & $23(44.2 \%)$ & $21(44.7 \%)$ & & & & \\
\hline Socio-economic Status* & & & 0.935 & 3 & & 0.426 \\
\hline Poor & $13(25 \%)$ & $10(21.3 \%)$ & & & & \\
\hline Lower middle class & $17(32.7 \%)$ & $17(36.2 \%)$ & & & & \\
\hline Upper middle class & $14(26.9 \%)$ & $14(29.8 \%)$ & & & & \\
\hline Rich & $8(15.4 \%)$ & $6(12.8 \%)$ & & & & \\
\hline
\end{tabular}

"Annual household income: $<10.000 €=$ poor; $10.001-30.000 €=$ lower middle class; $30.001-60.000 €=$ upper middle class; $>60.000 €=$ rich

Table2: Comparison of study group with healthy controls in age, gender, years of education, IQ, type of schools, and socio-economic status. 
Citation: Deveci E, Öztürk A, Kırpınar I, Koyuncu A, Engin I, et al. (2014) Neurocognition in Patients with Acne Vulgaris. J Psychiatry 17: 121 doi: $10.4172 / 2378-5756.10001214$

Page 4 of 7

\begin{tabular}{|c|c|c|c|c|c|c|}
\hline Neurocognitive Tests & Related Cognitive Functions & Acne group $(n=52)$ & Control group $(n=47)$ & Comparison (p) & $t$ & $d f$ \\
\hline Rey Verbal Learning and Memory Test & \multirow{2}{*}{ Verbal episodic memory and } & & & & & \\
\hline Total learning scores $(1-5) \mathbb{T}^{*}$ & & $49.57 \pm 7.75$ & $59.09 \pm 6.37$ & $<0.0001^{* *}$ & -6.62 & 97 \\
\hline Delayed recalling scores $(7)^{\S^{* *}}$ & learning & $9.96 \pm 1.93$ & $12.60 \pm 2.38$ & $<0.0001^{* *}$ & -6.00 & 88.6 \\
\hline True positives $¥$ & & $13.81 \pm 1.17$ & $14.15 \pm 1.33$ & 0.1787 & -1.35 & 97 \\
\hline Recognition percent correct score $\dagger$ & & $0.95 \pm 0.04$ & $0.97 \pm 0.04$ & $0.0475^{\star}$ & -2.01 & 97 \\
\hline Auditory Consonant Trigram Test Total scores ${ }^{* *}$ & Attention and working memory & $44.35 \pm 7.44$ & $52.32 \pm 4.98$ & $<0.0001^{* *}$ & -6.19 & 97 \\
\hline Controlled Word Association Test Total scores ${ }^{* *}$ & phonemic verbal fluency & $32.56 \pm 10.65$ & $45.72 \pm 13.53$ & $<0.0001^{* *}$ & -5.40 & 97 \\
\hline Digit Span Test & \multirow{2}{*}{ Attention and working memory } & & & & & \\
\hline Forwards section score ${ }^{* *}$ & & $5.88 \pm 1.62$ & $7.15 \pm 2.01$ & $0.0008^{* *}$ & -3.46 & 97 \\
\hline Backwards section score $^{* \star}$ & & $5.38 \pm 1.40$ & $6.79 \pm 2.13$ & $0.0002^{* *}$ & -3.91 & 97 \\
\hline Total scores ${ }^{* *}$ & & $11.27 \pm 2.47$ & $13.94 \pm 3.73$ & $<0.0001^{* *}$ & -4.15 & 78.5 \\
\hline Trail Making Test & \multirow{2}{*}{$\begin{array}{l}\text { mental flexibility and motor } \\
\text { abilities }\end{array}$} & & & & & \\
\hline Part A & & $28.59 \pm 8.95$ & $30.22 \pm 10.93$ & 0.4177 & -0.81 & 97 \\
\hline Part B & & $80.29 \pm 52.16$ & $67.02 \pm 34.99$ & 0.1372 & 1.47 & 89.7 \\
\hline Stroop Test Main Card $\ddagger$ Reading Time & mental flexibility & $22.64 \pm 7.64$ & $21.11 \pm 5.27$ & 0.2538 & 1.14 & 97 \\
\hline
\end{tabular}

$p<0.05$ (2-tailed). " $p<0.01$ (2-tailed).

I The total number of correctly recalled words summed over the five learning trials

$\S$ The number of correctly recalled words after the 20 min delay.

$¥$ The number of true answers that the subject was expected to mark in recognition section of the test.

† Calculated by the formula (True positives + True negatives)/50

¥ The card which contains words that are printed in colors different from those spelled out. The subject is asked to say the color of the ink.

Table 3: Comparison of study group with healthy controls according to cognitive tests and the cognitive functions related to the tests.

\begin{tabular}{|l|c|c|c|c|}
\hline & Acne group $(\mathrm{n}=52)$ & Control group $(\mathrm{n}=47)$ & Comparison $(p)$ & $t$ \\
\hline HADS/Anxiety & $8.34 \pm 4.05$ & $6.26 \pm 2.77$ & $0.004^{* *}$ & 3.01 \\
\hline HADS/Depression & $5.12 \pm 2.61$ & $4.69 \pm 2.68$ & 0.319 & 90.42 \\
\hline LSAS /Anxiety* & $50.17 \pm 12.09$ & $42.60 \pm 9.58$ & $0.001^{* *}$ & 97 \\
\hline LSAS /Avoidance $^{* *}$ & $48.33 \pm 12.61$ & $37.57 \pm 8.93$ & $0.0001^{* *}$ & 3.42 \\
\hline
\end{tabular}

"* $p<0.01$ (2-tailed).

Table4: Comparisons between acne and control groups according to Hospital Anxiety and Depression Scale (HADS) and Liebowitz Social Anxiety Scale (LSAS) Scores.

\section{Hospital anxiety and depression and liebowitz social anxiety scale scores}

Acne patients scored higher than controls in Hospital anxiety, Liebowitz anxiety, and avoidance scales. There were no significant differences in the hospital depression scores between the control and acne groups (Table 4).

Analysis of covariance (ANCOVA) results of cognitive tests of acne and control group after correction for HADS and LSAS scores as covariates.

Taking into account that the groups were significantly different on measures of HADS anxiety and LSAS scores which might have influences on cognitive performance, we conducted Analysis of covariance (ANCOVA) to compare groups on cognitive functioning, controlling for HADS and LSAS scores. As seen on Table 5, the differences between the performances of the groups in cognitive assessment remained significant after covariance.

\section{Discussions}

The present study demonstrates that acne patients show worse performance in verbal episodic memory, learning, working memory, and phonemic verbal fluency in comparison with controls. No group difference was found in cognitive tests assessing attention or executive functions. We found two studies concerned with cognitive functioning in acne vulgaris patients [22,23]. In addition, our recent study showed improvements in cognitive abilities such as attention and executive functions, during isotretinoin treatment [11]. In the first study, working memory and verbal fluency were tested in acne patients using the digit span backward, forward, digit symbol, and letter fluency tests and were found to be significantly improved after isotretinoin treatment [22]. In the second study, hippocampal-based learning was evaluated using the Cambridge Neuropsychological Test Automated Battery (CANTAB) and was found to be improved significantly after isotretinoin treatment [23].

The active metabolite of isotretinoin, retinoic acid (RA), is synthesized endogenously from vitamin A and acts to regulate cellular proliferation and differentiation, neuronal plasticity, long-term potentiation (LTP), and neurogenesis in the central nervous system (CNS). The hippocampus plays a critical role in episodic and spatial memory, which are dependent on RA regulated functions, such as neuronal plasticity, long-term potentiation, and neurogenesis [24]. $\mathrm{RA}$ is also required for neurogenesis in the hippocampus, inducing the expression of neurotrophin receptors [25], and promoting neuronal differentiation and cell survival [23]. The positive influence 
Citation: Deveci E, Öztürk A, Kırpınar I, Koyuncu A, Engin I, et al. (2014) Neurocognition in Patients with Acne Vulgaris. J Psychiatry 17: 121 doi: 10.4172/2378-5756.10001214

Page 5 of 7

\begin{tabular}{|c|c|c|c|c|c|}
\hline Dependent Variable & Sum of Squares & df & Mean Square & $\mathrm{F}$ & $p$ \\
\hline \multicolumn{6}{|l|}{ Rey Verbal Learning and Memory Test } \\
\hline Total learning scores $(1-5) \prod^{*}$ & 987.315 & 1 & 987.315 & 24.867 & $<0.001$ \\
\hline Delayed recalling scores $(7) \S^{\star *}$ & 79.555 & 1 & 79.555 & 20.876 & $<0.001$ \\
\hline True positives $*$ & 0.002 & 1 & 0.002 & 0.01 & 0.970 \\
\hline Recognition percent correct score $†$ & 0.001 & 1 & 0.001 & 0.722 & 0.398 \\
\hline Auditory Consonant Trigram Test Total scores ${ }^{\star *}$ & 1211.832 & 1 & 1211.832 & 29.177 & $<0.001$ \\
\hline Controlled Word Association Test Total scores* & 2324.689 & 1 & 2324.689 & 15.917 & $<0.001$ \\
\hline \multicolumn{6}{|l|}{ Digit Span Test } \\
\hline Forwards section score $^{* *}$ & 29.732 & 1 & 29.732 & 9.085 & 0.003 \\
\hline Backwards section score $^{* *}$ & 27.599 & 1 & 27.599 & 8.538 & 0.004 \\
\hline Total scores* & 114.621 & 1 & 114.621 & 11.695 & 0.001 \\
\hline \multicolumn{6}{|l|}{ Trail Making Test } \\
\hline Part A & 176.100 & 1 & 176.100 & 1.782 & 0.185 \\
\hline Part B & 731.013 & 1 & 731.013 & 0.401 & 0.528 \\
\hline Stroop Test Main Card $\ddagger$ Reading Time & 16.307 & 1 & 16.307 & 0.362 & 0.549 \\
\hline
\end{tabular}

${ }^{*} p<0.05$ (2-tailed). ${ }^{*} p<0.01$ (2-tailed).

II The total number of correctly recalled words summed over the five learning trials

$\S$ The number of correctly recalled words after the 20 min delay.

$¥$ The number of true answers that the subject was expected to mark in recognition section of the test.

† Calculated by the formula (True positives + True negatives)/50

¥ The card which contains words that are printed in colors different from those spelled out. The subject is asked to say the color of the ink.

Table 5: ANCOVA results of cognitive tests of acne and control group after correction for Hospital Anxiety and Depression Scale (HADS) and Liebowitz Social Anxiety Scale (LSAS) scores as covariates.

of isotretinoin on cognition could be due to either its impact on hippocampal function related with retinoid signalling, or alleviation of acne and consequently the reduction in psychological disturbances.

In a retrospective cross-sectional study of epidemiologic databases of 55,825 dermatology outpatient visits from 1995 to 2009, Gupta et al. [26] examined the frequency of Attention Deficit Hyperactivity Disorder (ADHD) in acne versus all other dermatology-related patient visits, and reported that in comparison to other dermatologic disorders, acne was over two-fold more likely to be associated with ADHD, after controlling for the possible confounding effects of age, sex, stimulant medications, co-morbid anxiety, or depressive disorders. Given that attention deficit/hyperactivity disorder has been associated with disturbances of cognitive functions, such as working memory, attention and executive functions, the higher frequency of ADHD in acne patients suggests a relationship between acne and cognitive dysfunctions [2729]. Gupta et al. [26] also suggest that the significant association of acne with ADHD may contribute to the increased psychological morbidity observed in some acne patients. However we did not find any group differences in cognitive tests assessing attention or executive functions. This might be due to our exclusion criteria including ADHD, family history (first degree relatives) of schizophrenia, bipolar disorder or schizoaffective disorder which is affecting mainly attention or executive functions. On the other hand, our finding that specific cognitive functions in acne patients are influenced might be due to some causes. The psychological distresses which can lead to dysfunctions in cognition, including decreased self-esteem, impaired perception of selfimage, embarrassment, fear of rejection, social withdrawal, and anger, restrictions in lifestyle, problematic family relations, excessive mental engagement in the acne lesions, and depressive and anxiety symptoms can be considered to be the most relevant within these causes. Skaali et al. [30] reported that the level of cancer-related distress in recently diagnosed testicular cancer patients may be related to cognitive impairments. Similarly, Hart et al. [31] examined the role of emotional distress in causing the cognitive impairment that often is apparent in patients with chronic pain, and suggested that pain-related negative emotions and stress may impact cognitive functioning independent of the effects of pain intensity. However, as seen on Table 5, the differences between the performances of the groups in cognitive tests remained significant after controlling for HADS and LSAS scores, which may suggest underlying mechanisms other than psychological distress.

The current study did not test the role of the factors other than psychological distress in performances of acne patients in cognitive tests, but accepting that alternative hypotheses remain just as plausible, we offer oxidative stress (OS) which plays roles in the etiopathogenesis of some dermatological diseases, and significantly impacts neuronal viability and neuroplasticity as a candidate mechanism. OS is defined as "a disturbance in the pro-oxidant-antioxidant balance in favour of the former, leading to potential damage" [32]. Recent studies have concluded that OS plays a pivotal role in the pathogenesis of acne vulgaris, and that increased cutaneous and systemic OS has been shown in the patients with acne [33-35]. The brain is markedly sensitive to oxidative damage since (a) it has a high proportion of polyunsaturated fatty acids, which are highly vulnerable to lipid peroxidation and catecholamines sensitive for autoxidation; (b) it has a high metabolic activity, due to its dependence on large amounts of oxygen; (c) it has a lower activity of glutathione peroxidase and catalase, when compared to other organs, which means it is relatively deficient in antioxidant systems; and (d) its metal components, such as copper and iron, are redox-active metals, which result to the production of free radicals [36]. Recent data also suggest that OS may be involved in the pathophysiology of psychiatric disorders, such as bipolar disorder, schizophrenia, depressive disorders, and anxiety disorder [37]. OS can also cause neuronal toxicity via DNA damage, lipid peroxidation, and reduction in neurotrophins. In the light of these data, OS may be a candidate mechanism responsible for the neuro-structural and cognitive changes in major psychiatric disorders and cognitive disturbances in acne patients, which should be investigated in future studies $[38,39]$.

There are two important limitations of the present study. Firstly, the test batteries did not include all areas of cognitive functioning. This is 
a consequence of the time required for completion of the test battery. On average, 1 hour was required to complete our battery of tests, and longer test times may have resulted in a fatigue-related decrease in performance. The next limitation was that the visible nature of acne lesions made it impossible to perform the neurocognitive evaluations blind.

In conclusion, we found that cognitive functions are influenced in acne patients with a worse performance when compared to a control group. We suggest that this influence may be related to the psychological distress associated with acne vulgaris, and the underlying metabolic/chemical pathways affecting both the skin and the brain may be related to retinoid signalling, or OS. As acne vulgaris is a disease of adolescence, when academic performance has great importance, psychiatric consultation including cognitive evaluation seems to be critical part of acne treatment.

Further investigations are necessary to develop the links between cognitive functioning and oxidative parameters in acne patients. Neuroimaging studies focusing on the hippocampus and prefrontal cortex should verify our data, and shed further light on the pathogenesis of the impact of acne on the cognitive functions.

\section{Acknowledgements}

The authors declare that they have no competing interests to report. The study was not supported by any funding sources. This study is presented as a poste abstract at the 5th International Congress on Psychopharmacology \& Internationa Symposium on Child and Adolescent Psychopharmacology 2013.

\section{References}

1. Öztürk A, Deveci E, Bağcioğlu E, Atalay F, Serdar Z (2013) Anxiety, depression, social phobia, and quality of life in Turkish patients with acne and their relationships with the severity of acne. Turkish Journal of Medical Sciences 43: $660-666$.

2. Hanna S, Sharma J, Klotz J (2003) Acne vulgaris: more than skin deep Dermatol Online J 9: 8

3. Rubinow DR, Peck GL, Squillace KM, Gantt GG (1987) Reduced anxiety and depression in cystic acne patients after successful treatment with oral isotretinoin. J Am AcadDermatol 17: 25-32.

4. Aktan S, Ozmen E, Sanli B (2000) Anxiety, depression, and nature of acne vulgaris in adolescents. Int J Dermatol 39: 354-357.

5. Kellett SC, Gawkrodger DJ (1999) the psychological and emotional impact of acne and the effect of treatment with isotretinoin. $\mathrm{Br} \mathrm{J}$ Dermatol 140: 273-282.

6. Saitta P, Keehan P, Yousif J, Way BV, Grekin S, et al. (2011) An update on the presence of psychiatric comorbidities in acne patients, Part 2: Depression, anxiety, and suicide. Cutis 88: 92-97.

7. Bowe WP, Logan AC (2011) Acne vulgaris, probiotics and the gut-brain-skin axis - back to the future? Gut Pathog 3: 1.

8. Mallon E, Newton JN, Klassen A, Stewart-Brown SL, Ryan TJ, et al. (1999) The quality of life in acne: a comparison with general medical conditions using generic questionnaires. $\mathrm{Br} J$ Dermatol 140: 672-676.

9. O'Toole MS, Pedersen AD (2011) A systematic review of neuropsychological performance in social anxiety disorder. Nord J Psychiatry 65: 147-161.

10. Beblo T, Exner C (2010) regarding the search for a specific neuropsychological profile in depression: limits and perspectives. Neuropsychiatr 24: 234-242.

11. Deveci E, Öztürk A, Kirpinar I, Engin RI, Melikoglu M, et al. (2013) Improvement in attention and executive functions during isotretinoin treatment in patients with acne. Türkderm:derihastalıklarvefrengiarşivi 47: 109-113.

12. Harris ME, Ivnik RJ, Smith GE (2002) Mayo's Older Americans Normative Studies: expanded AVLT Recognition Trial norms for ages 57 to 98 . J ClinExpNeuropsychol 24: 214-220.

13. Strauss E, Sherman EMS, Spreen O (2006) a Compendium of Neuropsychological Tests: Administration, Norms, and CommentaryNewYork: Oxford University Press.
14. UmaçA (1997) Normal deneklerde frontal hasarlaraduyarlıbazıtestlerdeperform ansayaşveeğitiminetkisi., in Sosyal Bilimler Enstitüsü Psikoloji Bölümülstanbul Üniversitesi Istanbul.

15. Deveci E, Ozan E, Kirpinar I, Oral M, Daloğlu AG, et al. (2013) Neurocognitive functioning in young high-risk offspring having a parent with bipolar I disorder. Turkish Journal of Medical Sciences 43: 110-117.

16. Reitan R, Wolfson D (1985) the Halstead-Reitan Neuropsychological Test BatteryTucson AZ. Neuropsychological Press.

17. Ozan E, Deveci E, Oral M, Karahan U, Oral E, et al. (2010) Neurocognitive functioning in a group of offspring genetically at high-risk for schizophrenia in Eastern Turkey. Brain Res Bull 82: 218-223.

18. Özkürkçügil A, Aydemir Ö, Yıldız M, Danacı E, Köroğlu E (1999) DSM-IV Eksen I BozukluklarılçinYapılandırılmışKlinikGörüşmeninTürkçe'yeUyarlanmasıveGü venilirlikÇalışması. İlaçveTedaviDerg 12: 233-236.

19. Aydemir Ö, Güvenir T, Küey L, Kültür S (1997) HastaneAnksiyeteveDepresy onÖlçeğiTürkçeFormununGeçerlilikveGüvenilirliği. Turk PsikiyatriDerg 8: 280 287

20. Soykan C, Ozguven HD, Gencoz T (2003) Liebowitz Social Anxiety Scale: the Turkish version. Psychol Rep 93: 1059-1069.

21. Gollnick H, Orfanos C (1993) Clinical assessment of acne, in Acne, W. Cunliffe, Editor Hippokrates: Stuttgart. 118

22. Ergun T, Seckin D, Ozaydin N, Bakar O, Comert A, et al. (2012) Isotretinoin has no negative effect on attention, executive function and mood. J EurAcad Dermatol Venereol 26: 431-439.

23. Ormerod AD, Thind CK, Rice SA, Reid IC, Williams JH, et al. (2012) Influence of isotretinoin on hippocampal-based learning in human subjects. Psychopharmacology (Berl) 221: 667-674

24. McCaffery P, Zhang J, Crandall JE (2006) Retinoic acid signaling and function in the adult hippocampus. J Neurobiol 66: 780-791.

25. Takahashi J, Palmer TD, Gage FH (1999) Retinoic acid and neurotrophins collaborate to regulate neurogenesis in adult-derived neural stem cell cultures. J Neurobiol 38: 65-81.

26. Gupta MA, Gupta AK, Vujcic B (2014) Increased frequency of Attention Deficit Hyperactivity Disorder (ADHD) in acne versus dermatologic controls: analysis of an epidemiologic database from the US. J Dermatolog Treat 25: 115-118.

27. Takacs A, Kobor A, Tarnok Z, Csepe V (2013) Verbal fluency in children with ADHD: Strategy using and temporal properties. Child neuropsychol 4: 4 .

28. Kasper LJ, Alderson RM, Hudec KL (2012) Moderators of working memory deficits in children with attention-deficit/hyperactivity disorder (ADHD): a metaanalytic review. ClinPsychol Rev 32: 605-617.

29. Brown TE (2008) ADD/ADHD and Impaired Executive Function in Clinica Practice. Current psychiatry reports 10: 407-411.

30. Skaali T, Fossa SD, Andersson S, Langberg CW, Lehne G, et al. (2011) is psychological distress in men recently diagnosed with testicular cancer associated with their neuropsychological test performance? Psychooncology 20: 369-377.

31. Hart RP, Wade JB, Martelli MF (2003) Cognitive impairment in patients with chronic pain: the significance of stress. Current pain and headache reports 7 : 116-126.

32. Sies H (1991) Oxidative stress: from basic research to clinical application. Am J Med 91: 31S-38S.

33. Sarici G, Cinar S, Armutcu F, Altinyazar C, Koca R, et al. (2010) Oxidative stress in acne vulgaris. J EurAcadDermatolVenereol 24: 763-767.

34. Briganti S, Picardo M (2003) Antioxidant activity, lipid peroxidation and skin diseases. What's new. J EurAcadDermatolVenereol 17: 663-669.

35. Bowe WP, Logan AC (2010) Clinical implications of lipid peroxidation in acne vulgaris: old wine in new bottles. Lipids Health Dis 9: 141

36. Mangialasche F, Polidori MC, Monastero R, Ercolani S, Camarda C, et al (2009) Biomarkers of oxidative and nitrosative damage in Alzheimer's disease and mild cognitive impairment. Ageing Res Rev 8: 285-305.

37. Berk M, Ng F, Dean O, Dodd S, Bush Al (2008) Glutathione: a novel treatment target in psychiatry. Trends PharmacolSci 29: 346-351. 
Citation: Deveci E, Öztürk A, Kırpınar I, Koyuncu A, Engin I, et al. (2014) Neurocognition in Patients with Acne Vulgaris. J Psychiatry 17: 121 doi: 10.4172/2378-5756.10001214

Page 7 of 7

38. Halliwell B (2006) Oxidative stress and neurodegeneration: where are we now? J Neurochem 97: 1634-1658.
39. Ng F, Berk M, Dean O, Bush Al (2008) Oxidativestress in psychiatric disorders: evidence base and therapeutic implications. Int J Neuropsychopharmacol 11: 851-876. 